\title{
Internal friction associated with the microstructural changes in an AZ91 magnesium alloy
}

\author{
Z. Trojanová ${ }^{1 *}$, P. Palček ${ }^{2}$, A. Soviarová ${ }^{2}$, M. Chalupová ${ }^{2}$, K. Dash ${ }^{3}$, M. Knapek ${ }^{1}$ \\ ${ }^{1}$ Department of Physics of Materials, Faculty of Mathematics and Physics, Charles University in Prague, \\ Ke Karlovu 5, 12116 Prague 2, Czech Republic \\ ${ }^{2}$ Department of Materials Engineering, Faculty of Mechanical Engineering, University of Žilina, \\ Univerzitná 8215/1, 01026 Žilina, Slovak Republic \\ ${ }^{3}$ Department of Materials, University of Oxford, Parks Road, Oxford OX1 3PH, U.K.
}

Received 11 February 2015, received in revised form 21 May 2015, accepted 21 May 2015

\begin{abstract}
Temperature dependence of logarithmic decrement was measured in Mg-9Al-1Zn alloy. The developed internal friction peak was found while heating in the vicinity of $320^{\circ} \mathrm{C}$. Position and height of this peak in the temperature scale depends on the heating rate. Simultaneously microstructural observations were performed in the selected points of the temperature scale. SEM revealed discontinuous precipitates at lower temperature which converted at higher temperatures into continuous precipitates. Possible internal friction mechanism is discussed.
\end{abstract}

K e y w o r d s: magnesium alloy, internal friction, precipitation, SEM

\section{Introduction}

$\mathrm{Mg}-\mathrm{Al}-\mathrm{Zn}$ alloys belong to the most used magnesium materials. Although precipitation phenomena in these alloys have been investigated extensively, there are still phenomena which are not clear enough. The majority of the research has been concentrated on age hardening [1-3]. Precipitation processes may be studied using standard imaging techniques. On the other hand the connection between microstructure changes and physical quantities such as electrical resistivity, internal friction or positron annihilation can be used. Research of precipitation on damping characteristics has been studied in several studies [4-6]. Precipitation exhibits different effects on internal friction of the alloys and the correlation between internal friction and precipitation has been considered to be quite complex [7].

Microstructure of an $\mathrm{Mg}-\mathrm{Al}$ alloy according to the binary equilibrium diagram consists of $\delta$ solid solution of $\mathrm{Al}$ in $\mathrm{Mg}$ and $\gamma-\mathrm{Mg}_{17} \mathrm{Al}_{12}$ (called also $\beta$ ) precipitation phase. This phase exhibits bcc structure with the lattice parameter of $1.05438 \mathrm{~nm}$ [8]. Morphology of $\gamma$-precipitates may be changed using different thermal treatment [9]. Commercial ternary alloys $\mathrm{Mg}-\mathrm{Al}-\mathrm{Zn}$ exhibit no new phases when the $\mathrm{Al}$ to $\mathrm{Zn}$ ratio is larger than $3: 1$ [2]. In this case, ternary compounds as $\mathrm{Mg}_{17} \mathrm{Al}_{11.5} \mathrm{Zn}_{0.5}$ or $\mathrm{Mg}_{17}(\mathrm{Al}, \mathrm{Zn})_{12}$ are formed $[10,11]$. During the ageing process, $\gamma$ phase is formed in two modifications: the discontinuous (DP) and continuous $(\mathrm{CP})$ precipitates. $\mathrm{Xu}$ and co-workers showed that the $\mathrm{Mg}_{12} \mathrm{Al}_{12} \mathrm{DP}$ may effectively prevent the grain growth during the grains refinement via dynamic recrystallisation [9]. Commercial AZ91 alloy usually contains $0.2-0.3 \mathrm{wt} . \%$ of $\mathrm{Mn}$ for the grains refinement. $\mathrm{Mn}$ atoms do not enter during the homogenisation treatment into intermetallic compounds with $\mathrm{Al}$ (for example $\mathrm{Al}_{8} \mathrm{Mn}_{5}$ ) [1].

Internal friction measurements were used in this study with the aim to give more complex picture of the precipitation process in the AZ91 magnesium alloy. SEM elucidated the thermodynamic processes occurring in the alloy during heating.

\section{Experimental procedure}

Gravity cast magnesium alloy AZ91 was used in this study. Chemical composition of the alloy is introduced in Table 1. Light micrograph of the as cast 
Table 1. Chemical composition of the alloy studied (wt.\%)

\begin{tabular}{|c|c|c|c|c|c|c|c|c|c|}
\hline Element & $\mathrm{Al}$ & $\mathrm{Zn}$ & $\mathrm{Mn}$ & $\mathrm{Ca}$ & $\mathrm{Si}$ & $\mathrm{Fe}$ & $\mathrm{Cu}$ & $\mathrm{Ni}$ & $\mathrm{Mg}$ \\
\hline & 8.050 & 0.637 & 0.242 & 0 & 0.023 & 0.016 & 0.005 & 0.001 & Balance \\
\hline
\end{tabular}
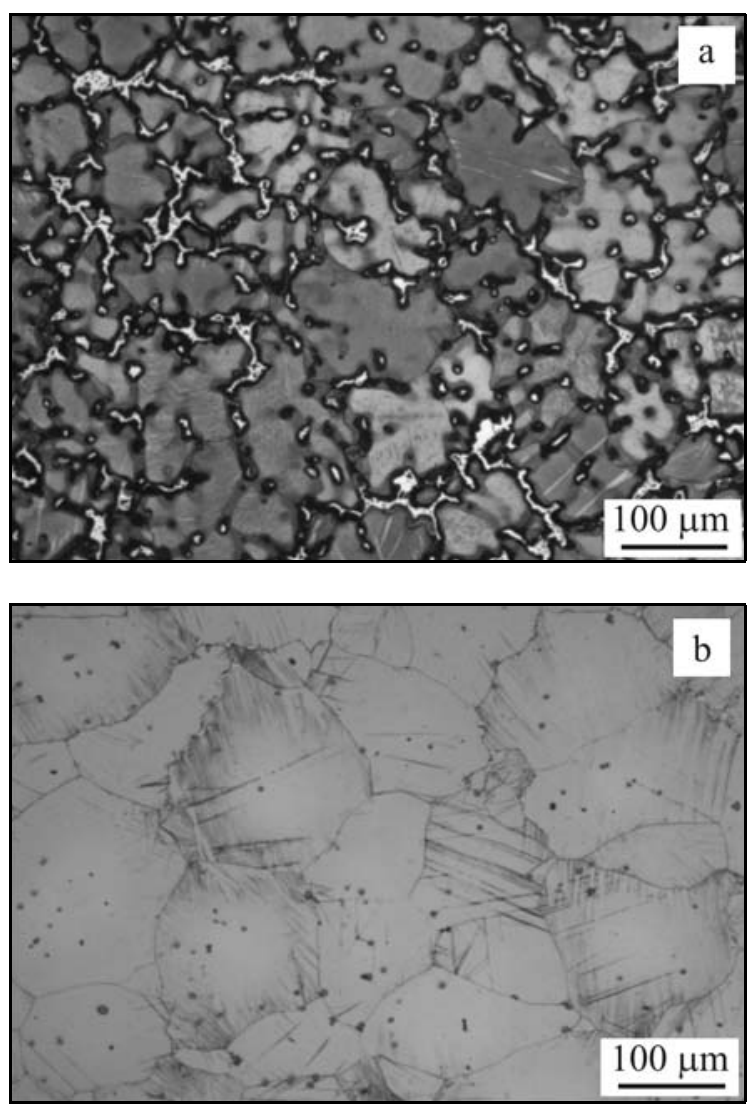

Fig. 1. Microstructure of the as cast alloy (a) and after thermal treatment $\mathrm{T} 4(\mathrm{~b})$.

sample, introduced in Fig. 1a, shows typical dendritic structure characterised by heavy segregation of the alloying elements. Solution treatment T4 (annealing for $22 \mathrm{~h}$ at $390^{\circ} \mathrm{C}$ and quenching into water of $60^{\circ} \mathrm{C}$ ) caused total dissolution of the $\gamma$ phase. The time necessary for the homogenisation of the alloy and formation of supersaturated $\delta$ solid solution is relatively long because of slow diffusion rate of $\mathrm{Al}$ in $\mathrm{Mg}$ in the solid state. Microstructure of the sample after T4 thermal treatment is introduced in Fig. 1b. It is obvious that the dendrites existing in the as cast sample were fully dissolved. Some annealing twins are visible in Fig. 1b.

The Resonant Frequency and Damping Analyser (RFDA) was used to determine the damping and resonant frequency. The measurements were performed in a wide temperature interval from room temperature up to $400^{\circ} \mathrm{C}$. The prism shaped samples $75 \times 20 \times 10 \mathrm{~mm}^{3}$ were excited to vibrations in the
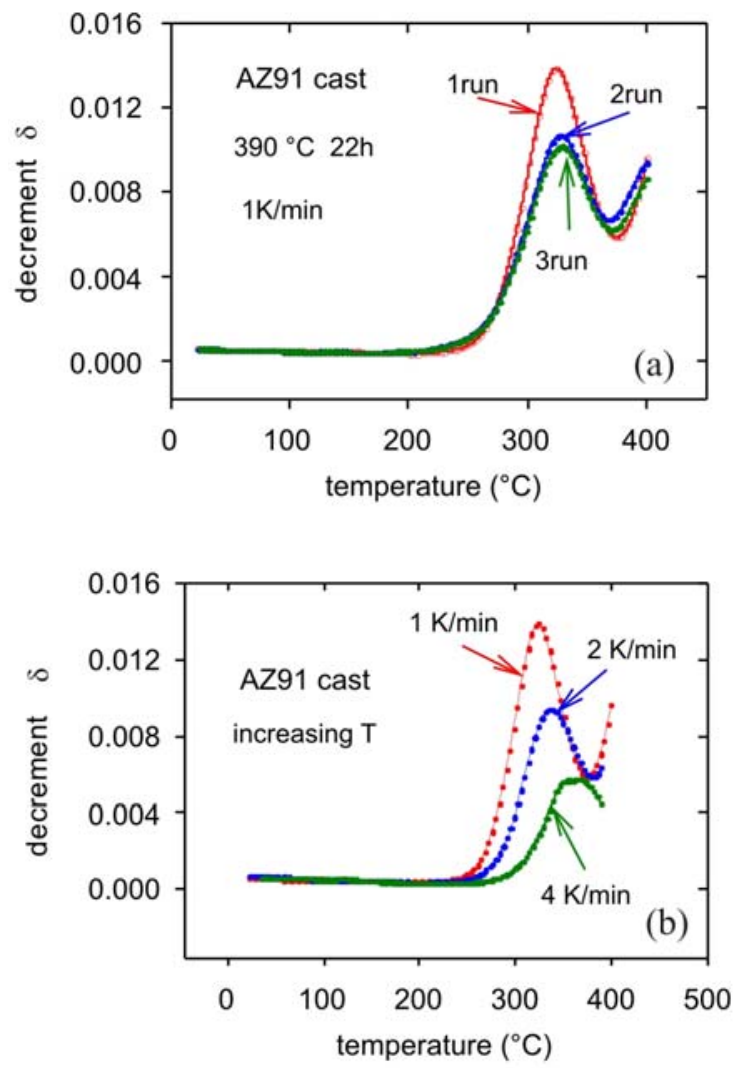

Fig. 2. Temperature dependence of the logarithmic decrement while heating performed in three runs for the heating rate $1 \mathrm{~K} \mathrm{~min}^{-1}$ (a) and for three heating rates (b).

resonant frequency using a small striker. Damping of the sample free vibrations was registered with a microphone and processed using special software. The resonant frequency exhibiting $\sim 8 \mathrm{kHz}$ was estimated by means of Fourier transform. The linear heating rate was chosen in the interval from 1 to $4 \mathrm{~K} \mathrm{~min}^{-1}$.

Microstructure of as cast and homogenised samples was studied using light microscope NEOPHOT 32. Details of the discontinuous and continuous precipitations were analysed in the scanning electron microscope TESCAN VEGA LMU II.

\section{Experimental results}

\subsection{Internal friction measurements}

Temperature dependence of the logarithmic decre- 
ment measured in the sample after the thermal treatment T4 while heating is introduced in Fig. 2a. The heating rate was $60 \mathrm{~K} \mathrm{~h}^{-1}$, the cooling rate was not controlled. The temperature record showed the linear decrease of temperature up to $120-140{ }^{\circ} \mathrm{C}$. When room temperature was reached a new measurement was started. The measurements were repeated three times. From Fig. 2a it is obvious that the decrement is more or less constant up to approximately $220^{\circ} \mathrm{C}$, then it increases with increasing temperature. At temperature $\sim 320^{\circ} \mathrm{C}$ a local maximum of the logarithmic decrement is observed. The height of this maximum decreases in the second and third run of the measurement. Observed maximum position in the temperature axis is the same for all runs. Temperature dependence of the logarithmic decrement was measured for three heating rates as it is introduced in Fig. 2b. Note that before each measurement a new $\mathrm{T} 4$ thermal treatment was performed. In Fig. $2 b$ only the first runs of the measurements are introduced. The higher heating rate, the higher temperature of the local maximum is observed. The height of the maximum simultaneously decreases with the increasing heating rate. To reveal the physical nature of the observed local maximum in the temperature dependence of the logarithmic decrement, an experiment on the sample with smaller thickness was performed. Maximum position in the temperature scale was not shifted for the measurement with the resonant frequency of $\sim 7 \mathrm{kHz}$. This fact indicates that observed maximum is not of the Debye type. Some transitory effects must be considered.

\subsection{Microstructure observations}

In the temperature dependence of the logarithmic decrement four characteristic points have been selected: $220,320,360$ and $390^{\circ} \mathrm{C}$. Samples were subjected to the T4 thermal treatment, then put into the furnace with the predetermined heating rate of $1 \mathrm{~K} \mathrm{~min}^{-1}$. Reaching the chosen temperature, samples were step by step removed from the furnace and quenched into water of $60^{\circ} \mathrm{C}$. SEM observations were performed at room temperature.

After heating of the sample with the heating rate of $1 \mathrm{~K} \mathrm{~min}^{-1}$ up to $220^{\circ} \mathrm{C}$ supersaturated solid solution decomposed; DP appeared in the vicinity of Mn (light) particle as it is obvious from Fig. 3a. The lamellae of the DP apparently grow directly from the interface between Mn particle and $\delta$ solid solution. DP rises from the grain boundary as it is obvious from Fig. 3b, small precipitates visible as light points are $\mathrm{CP}$, their size slowly increased. Tiny CPs are situated primarily in the annealing twins, the matrix in the vicinity of twins is purified, density of CPs is in these places lower (Fig. 3c).

When temperature increased up to $320^{\circ} \mathrm{C}$, decomposition of DPs started followed by the growing of CPs
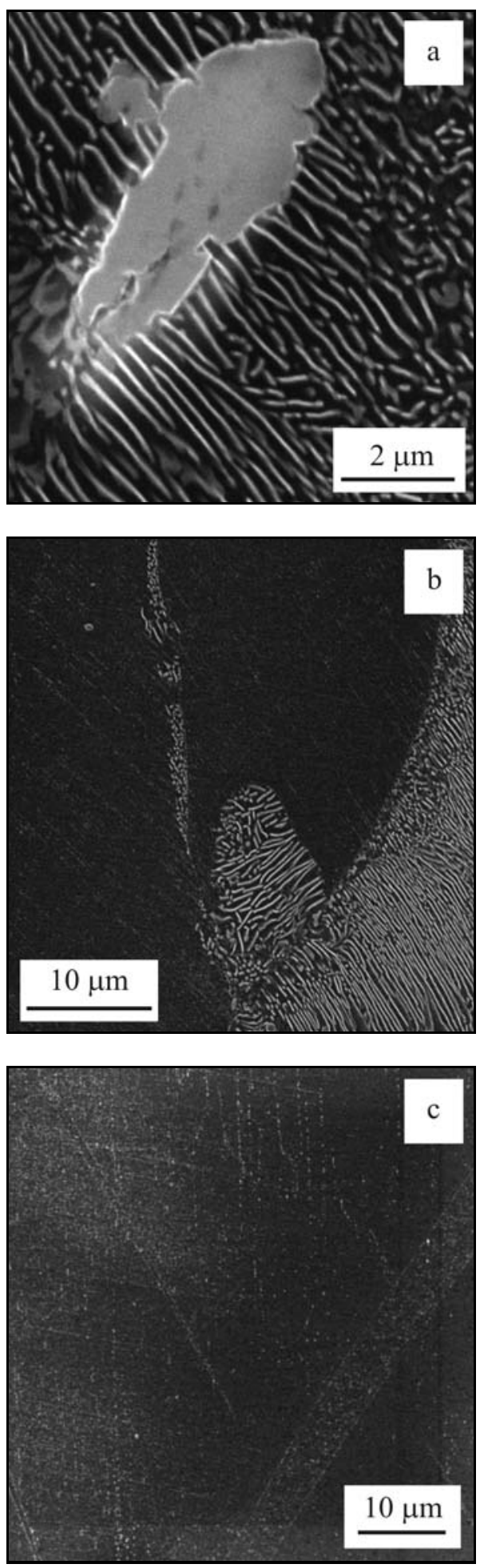

Fig. 3. Microstructure of the alloy observed after T4 annealing and linear heating up to $220^{\circ} \mathrm{C}$ : Mn particle (a), discontinuous precipitates (b), tiny continuous precipitates (c).

(Fig. 4a). Original lamellae were reshaped into small discs as it is visible from Fig. 4b. CPs depicts the twin, small discs of CPs are ordered in twin/grain boundar- 

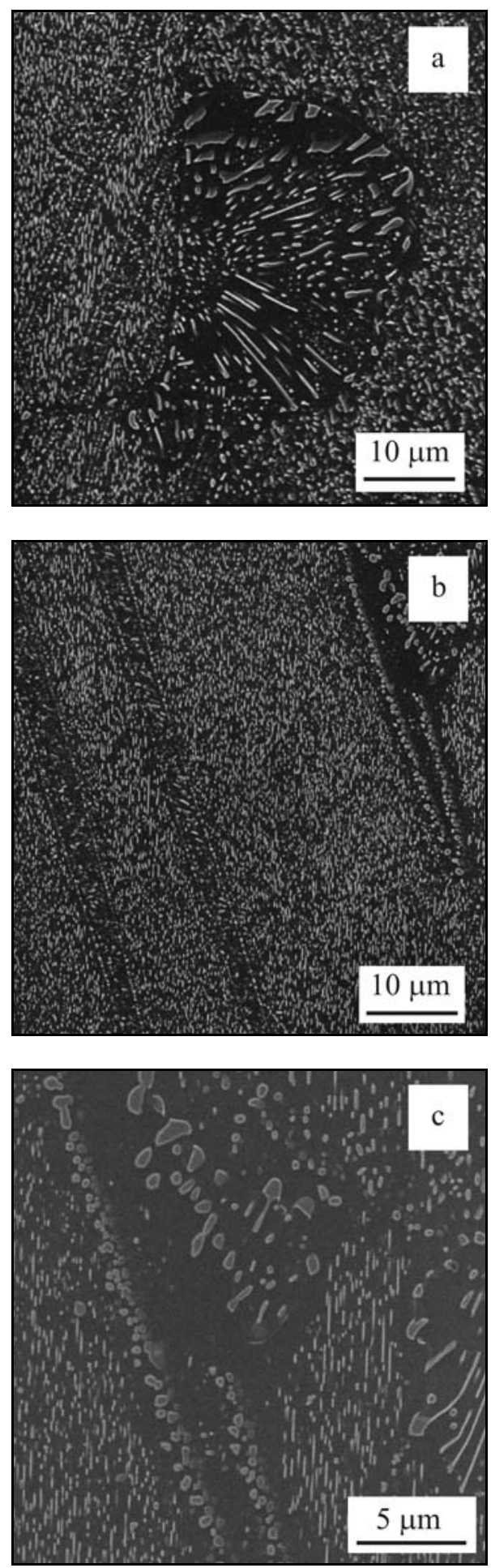

Fig. 4. Microstructure of the sample subjected to T4 thermal treatment and annealed up to $320^{\circ} \mathrm{C}$ : decomposition of the discontinuous precipitates (a), reshaping of lamellae into small discs (b), tiny continuous precipitates situated in the twin (c).

ies. Detail in Fig. 4c taken from the upper right corner of Fig. 4b shows arrangement of both types of precip-
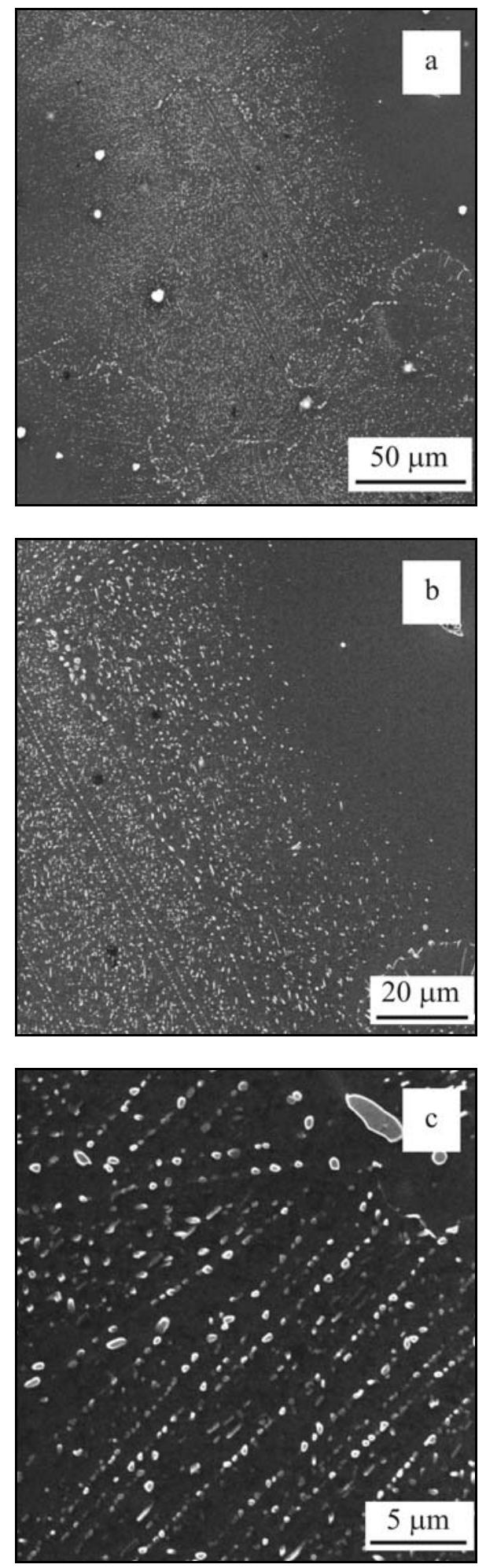

Fig. 5. Microstructure of the sample after T4 thermal treatment and annealed up to $360^{\circ} \mathrm{C}$ : growth of continuous precipitates (a), decorated grain boundaries (b), reshaping of discs into spheres (c).

itates. Note that temperature of $320^{\circ} \mathrm{C}$ corresponds to the peak temperature in the temperature dependence of decrement. 
Microstructure of the sample annealed up to $360^{\circ} \mathrm{C}$ (local minimum in the temperature dependence of decrement) is characterised by the growth of $\mathrm{CP}$ (Fig. 5a). Light points are small Mn particles. In the vicinity of grain boundaries purified places were established. Meander-like grain boundaries are decorated with bigger precipitates (Fig. 5b). Particle size of precipitates in the grain boundary increased (Fig. 5c), solute atoms were drawn from the surrounding areas. Small discs are reshaped into spheres (or globules).

At $390{ }^{\circ} \mathrm{C}$, the transformation of $\mathrm{DP}$ into $\mathrm{CP}$ is finished. The CPs decorate the grain boundaries (Fig. 6a), DP vanished as it is obvious from Fig. 6b and the size of CP increased (Fig. 6c). From the microstructure observation it is possible to conclude that in the temperature interval from 220 to $360^{\circ} \mathrm{C}$ a transformation of DP originally formed up to $220^{\circ} \mathrm{C}$ stepwise passed off. Disc shape CP changed into small spheres and at the highest temperatures into bigger particles with the complex shape. Increasing the heating rate, time for the transformation of $\mathrm{DP}$ into $\mathrm{CP}$ is shorter. It is very probably the reason why the maximum height decreases with the increasing heating rate and at the same time the maximum is shifted to higher temperatures. DPs are formed when the grain boundary diffusion is dominant whereas the CPs are formed at higher temperatures from solid solution when volume diffusion becomes faster.

\section{Discussion}

Internal friction, i.e. damping of sonic or ultrasonic waves, is considered as the dissipation of the mechanical energy into thermal energy due to some intrinsic processes in a material. Internal friction is very sensitive to the material microstructure, volume fraction and distribution of structural defects. Any modification in the microstructure induces changes in the internal friction course. Then the internal friction measurements may provide information about processes occurring at the atomic scale $[12,13]$. Internal friction in AZ91 alloys was studied by several authors [4, 5, 14]. Lambri and co-workers [14] found the internal friction peak at approximately $152^{\circ} \mathrm{C}$ using the measuring frequency of $1 \mathrm{~Hz}$. Authors ascribed this peak to the grain boundary sliding. The peak height may be controlled by the decrease of the solute atoms due to precipitation process. Activation energy estimated from the Arrhenius plot was evaluated as $1.13 \mathrm{eV}$. Similarly Liu et al. [5] estimated for the internal friction peak situated at $165^{\circ} \mathrm{C}$ and frequency of $1 \mathrm{~Hz}$ and determined the corresponding activation energy of $1.26 \mathrm{eV}$. The peak was ascribed to the grain boundary relaxation. Authors of [5] considered that the background of internal friction is influenced by the precipitation in the matrix. Two internal friction peaks were ob-
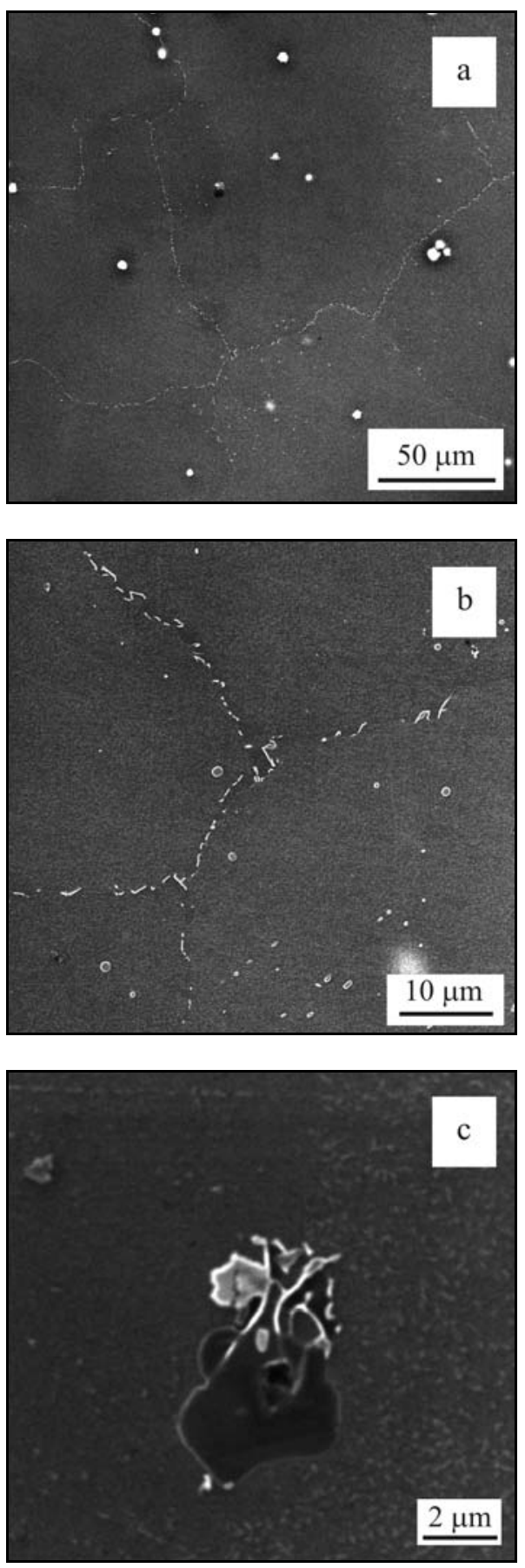

Fig. 6. Microstructure of the sample after T4 thermal treatment and annealing up to $390^{\circ} \mathrm{C}$ : decorating of grain boundaries with the continuous precipitates (a), (b); detail of the continuous precipitate (c).

served in [4]. $\mathrm{P}_{1}$ peak estimated at $165^{\circ} \mathrm{C}$ was characterised by the activation energy of $1.31 \mathrm{eV}$ and the high temperature $\mathrm{P}_{2}$ peak was found to be sensitive to the heating rate and insensitive to the measuring frequency. Authors of [4] ascribed this peak to the viscous sliding at the $\gamma-\mathrm{Mg}_{17} \mathrm{Al}_{12} / \delta$-Mg interphase. Analogous 
peak to the $\mathrm{P}_{2}$ internal friction peak was estimated also by Soviarová et al. $[15,16]$ at $320^{\circ} \mathrm{C}$, frequency of $20.4 \mathrm{kHz}$ and the heating rate of $1 \mathrm{~K} \mathrm{~min}^{-1}$. Theoretical models of the internal friction consider that transformations in the solid state may be manifested by internal friction peaks. Damping mechanism can be associated with the kinetics of atoms diffusing to evolving precipitates [18].

Summarising observed experimental data we may conclude:

- The maximum position in the temperature scale does not depend on frequency;

- The maximum height decreases with increasing frequency;

- The maximum position in the temperature scale depends on the heating rate $\dot{T}$.

The microstructural observations revealed in the temperature interval of the maximum occurrence the transformation of discontinuous precipitates into continuous.

From this experimental data following internal friction image may be constructed. Observed independence of the maximum position on frequency indicates that the Arrhenius equation does not take place in this case, i.e. the interface relaxation and diffusion processes may be excluded as the reason for the maximum occurrence. From the published data concerning the internal friction maxima, exclusive of some relaxation peaks, no frequency dependence was detected [17-19]. During the IF measurement, the movable $\gamma-\mathrm{Mg}_{17} \mathrm{Al}_{12} / \delta-\mathrm{Mg}$ interface consumes the work. This work is proportional to the friction and the movable space of the interface. When a new interface forms, defects (solute atoms, vacancies) diffuse and accumulate in the interface which leads to the gradual pinning of the interface. The movable space is a function of heating time, i.e. the heating rate. The mobile interface stabilises, so that the internal friction decreases.

\section{Conclusions}

Internal friction measurements after homogenisation annealing and microstructural observations in the AZ91 magnesium alloy showed these main results:

- Temperature relaxation spectrum of internal friction exhibits developed local maximum at the vicinity of $320^{\circ} \mathrm{C}$. The maximum height decreased in the second and third run while the maximum temperature remained the same.

- Position of the maximum was sensitive to the heating rate and insensitive to the frequency. Increasing the heating rate shifted the peak temperature to higher temperatures.

- Occurrence of the internal friction maximum is connected with the transformation of discontinuous precipitates to continuous ones. Strain (stress) sup- ported movement of the $\gamma-\mathrm{Mg}_{17} \mathrm{Al}_{12} / \delta$-Mg interface is very probably the reason for the absorption of mechanical energy carried by an ultrasonic wave.

\section{Acknowledgements}

The authors would like to dedicate the paper to Professor Pavel Lukáč on the occasion of his 80th birthday.

The authors are grateful for the support offered by the Czech and Slovak authorities under the Exchange Programme 7AMB14SK190/SK-CZ-2013-0076. Z. T. thanks the Technology Agency of the Czech Republic for financial support under grant TA03010188. P. P., A. S. and M. C. are grateful to the Ministry of Education and the Slovak Academy of Sciences for the support by the project VEGA No. $1 / 0683 / 15$.

\section{References}

[1] Braszczyńska-Malik, K. N.: J. Alloys Compd., 477, 2009, p. 870. doi:10.1016/j.jallcom.2008.11.008

[2] Buršík, J., Svoboda, J.: Microchim. Acta, 139, 2002, p. 39. doi: $10.1007 / \mathrm{s} 006040200036$

[3] Zhou, J. P., Zhao, D. S., Wang, R. H., Sun, Z. F., Wang, J. B., Gui, J. N., Zheng, O.: Mater. Lett., 61, 2007, p. 4707. doi:10.1016/j.matlet.2007.03.013

[4] Hao, G. L., Han, F. S., Wang, Q. Z., Wu, J.: Physica B, 391, 2007, p. 186. doi:10.1016/j.physb.2006.09.018

[5] Liu, S.-W., Jiang, H.-C., Li, X.-Y., Rong, L.-J.: Trans. Nonferrous Met. Soc. China, 20, 2010, p. 453. doi:10.1016/S1003-6326(10)60517-1

[6] Gonzalez-Martínez, R., Göken, J., Letzig, D., Steinhoff, K., Kainer, K. U.: J. Alloys Compd., 437, 2007, p. 127. doi:10.1016/j.jallcom.2006.07.085

[7] Zhang, Z., Zeng, X., Ding, W.: Mater. Sci. Eng. A, 392, 2005, p. 150. doi:10.1016/j.msea.2004.09.056

[8] Schobinger-Papamantellos, P., Fischer, P.: Naturwissenschaften, 57, 1970, p. 128.

[9] Xu, S. W., Matsumoto, N., Komado, S., Honma, T., Kojima, Y.: Mater. Sci. Eng. A, 517, 2009, p. 354. doi:10.1016/j.msea.2009.04.029

[10] Kleiner, S., Orgis, E., Beffort, O., Ugglowitzer, P. J.: Adv. Eng. Mater., 9, 2003, p. 653. doi:10.1002/adem.200300358

[11] Celotto, S., Bastow, T. J.: Acta Mater., 49, 2001, p. 41. doi:10.1016/S1359-6454(00)00305-0

[12] Nowick, A. S., Berry, B. S.: Anelastic Relaxation in Crystalline Solids. New York, Academic Press 1972.

[13] De Batist, R.: Internal Friction of Structural Defects in Crystalline Solids. Amsterdam, North-Holland Pub. 1972.

[14] Lambri, O. A., Riehemann, W., Trojanová, Z.: Scripta Mater., 45, 2001, p. 1365. doi:10.1016/S1359-6462(01)01171-X

[15] Soviarová, A., Palček, P., Trojanová, Z.: Manufacturing Technology, 14, 2014, p. 447.

[16] Palček, P., Soviarová, A., Trojanová, Z., Chalupová, M. Dresslerová, Z.: In: 18th International Workshop on Advances in Experimental Mechanics (IWAEM). 
Ljubljana, Center for Experimental Mechanics 2014, p. 268. ISBN 978-961-90250-7-9.

[17] Schaller, R., Fantozzi, G., Gremaud, G. (eds.): Mechanical Spectroscopy $Q^{-1}$ 2001: With Applications to Material Science. Uetikon, Trans. Tech. Publications Ltd. 2001. ISBN 0-87849-876-1.
[18] Song, Z., Kishimoto, S., Zhu, J., Wang, Y.: Solid State Communications, 139, 2006, p. 235.

doi:10.1016/j.ssc.2006.05.037

[19] Trojanová, Z., Bosse, M., Ziegmann, G., Mielczarek, A. Ferkel, H.: Key Eng. Mater., 319, 2006, p. 189. doi:10.4028/www.scientific.net/KEM.319.189 